\title{
Resource use trends in extracorporeal membrane oxygenation in adults: An analysis of the Nationwide Inpatient Sample 1998-2009
}

\author{
Bryan G. Maxwell, MD, MPH, ${ }^{a}$ Andrew J. Powers, MD, ${ }^{b}$ Ahmad Y. Sheikh, MD, ${ }^{c}$ \\ Peter H. U. Lee, MD, MPH, ${ }^{c}$ Robert L. Lobato, MD, MS, ${ }^{d}$ and Jim K. Wong, MD ${ }^{b}$
}

Objective: The study objective was to determine whether significant trends over time have occurred in resource use associated with the use of extracorporeal membrane oxygenation in critically ill adults.

\begin{abstract}
Methods: All adult admissions involving extracorporeal membrane oxygenation were examined by using the Nationwide Inpatient Sample database (years 1998-2009). Trends in volume, outcome, and resource use (including hospital charges, length of stay, and charges per day) were analyzed.
\end{abstract}

\begin{abstract}
Results: An estimated total of 8753 admissions involved extracorporeal membrane oxygenation over the study period. Overall length of stay was $18.3 \pm 1.3$ days. Total hospital charges averaged $\$ 344,009 \pm \$ 30,707$ per admission, with average charges per day of $\$ 40,588 \pm \$ 3099$. Cumulative national charges for extracorporeal membrane oxygenation admissions increased significantly from $\$ 109.0$ million in 1998 to $\$ 764.7$ million in $2009(P=.0016)$. Charges per patient and length of stay also increased significantly $(P=.0032$ and .0321 , respectively). The increasing trend in the number of extracorporeal membrane oxygenation admissions during the study period was not statistically significant $(P=.19)$. The post-cardiotomy group had more favorable outcomes and lower resource use. A shift was observed in the relative case-mix of extracorporeal membrane oxygenation admissions over the study period, with a relative decrease in the post-cardiotomy group and increases in the cardiogenic shock, respiratory failure, and lung transplant groups.
\end{abstract}

Conclusions: These results suggest that dramatic increases in resource use associated with extracorporeal membrane oxygenation are not solely the result of increased volume, but in part are due to a shift toward extracorporeal membrane oxygenation use in patient groups (other than in the post-cardiotomy setting) with greater resource use and worse outcomes. (J Thorac Cardiovasc Surg 2014;148:416-21)

丹 Supplemental material is available online.

Extracorporeal membrane oxygenation (ECMO) is a wellestablished but complex and resource-intensive lifesupport intervention for critically ill patients with cardiac or respiratory failure. ${ }^{1}$ ECMO therapy in adults was first used in 1972 in a case of acute post-traumatic respiratory failure. $^{2}$ Since that time, ECMO expanded to a widerange of life-support indications. Although adult patients represent a minority $(12.5 \%)$ of all ECMO records in the

\footnotetext{
From the Department of Anesthesiology and Critical Care Medicine, ${ }^{a}$ Johns Hopkins University School of Medicine, Baltimore, Md; Departments of Anesthesia ${ }^{\mathrm{b}}$ and Cardiothoracic Surgery, ${ }^{\mathrm{c}}$ Stanford University School of Medicine, Stanford, Calif; and Department of Anesthesia, ${ }^{\mathrm{d}}$ Cedars-Sinai Medical Center, Los Angeles, Calif. Funded by intramural support.

Disclosures: Authors have nothing to disclose with regard to commercial support. Received for publication Aug 1, 2013; revisions received Sept 2, 2013; accepted for publication Sept 17, 2013; available ahead of print Nov 4, 2013.

Address for reprints: Bryan G. Maxwell, MD, MPH, Department of Anesthesiology and Critical Care Medicine, Johns Hopkins University School of Medicine, 1800 Orleans St Zayed 6208P, Baltimore, MD 21287 (E-mail: bmaxwell@ jhu.edu). 0022-5223/\$36.00

Copyright (C) 2014 by The American Association for Thoracic Surgery http://dx.doi.org/10.1016/j.jtcvs.2013.09.033
}

international Extracorporeal Life Support Organization registry, they are a rapidly growing group.

Single institution reports and those including only the neonatal population have described the costs ${ }^{4,5}$ and costbenefit or cost-effectiveness analyses ${ }^{6,7}$ of ECMO, but multi-institutional studies on the use of ECMO in adults are lacking. ${ }^{8}$ More focused economic analyses ${ }^{9,10}$ have not provided information on trends over time in the resource use associated with ECMO use in adults.

We used an established, nationally representative administrative database to examine trends in resource use measures and in-hospital mortality in adults undergoing ECMO from 1998 to 2009, to test the hypothesis that changes in the numbers and makeup of this population have caused significant shifts in ECMO-associated resource use.

\section{MATERIALS AND METHODS}

The Stanford University Institutional Review Board granted an exemption from review because this research uses de-identified data. Administrative records were extracted from discharge datasets for the years 1998 to 2009 from the Nationwide Inpatient Sample (NIS), Healthcare Cost and Utilization Project, Agency for Healthcare Research and Quality. The NIS is the largest publicly available all-payer database for inpatient care in the United States. Each dataset year includes records on 7 to 8 million admissions from approximately 1000 hospitals in 44 states, which reflect 


\author{
Abbreviations and Acronyms \\ CPI = Consumer Price Index \\ ECMO = extracorporeal membrane \\ oxygenation \\ ICD-9-CM = International Classification of \\ Diseases, 9th Revision, Clinical \\ Modification \\ NIS $\quad=$ Nationwide Inpatient Sample
}

a $20 \%$ stratified sample of all US nonfederal, nonrehabilitation hospitals. ${ }^{11}$ It contains discharge sample weights to facilitate nationally representative estimates based on the sampling design. Although it contains limited, administrative data on each inpatient encounter, its size and sampling frame facilitates the analysis of comparatively rare clinical events at a national level.

Healthcare Cost and Utilization Project-supplied Clinical Classifications Software for the International Classification of Diseases, 9th Revision, Clinical Modification (ICD-9-CM) was used to generate diagnostic, comorbidity, and procedural classification codes. ECMO use was established using ICD-9-CM Volume 3 procedure codes 39.65 (extracorporeal membrane oxygenation) and 39.66 (percutaneous extracorporeal membrane oxygenation). These codes are explicitly exclusive of codes for cardiopulmonary bypass (used in the operating room for cardiac surgery) and hemodialysis. All adult (age $\geq 18$ years) admission records with an ECMO procedure code recorded were identified and sorted into 1 of 7 predefined groups, based on prior internal reviews and existing literature documenting categories of indications for ECMO use in adults: post-cardiotomy circulatory or respiratory failure (not including heart or lung transplant), ${ }^{12,13}$ preor post-heart transplant, ${ }^{14}$ pre- or post-lung transplant, ${ }^{15-18}$ cardiogenic shock/circulatory failure (outside of the context of cardiac surgery), respiratory failure and severe lung disease (not including lung transplantation), ${ }^{19-21}$ trauma/hypothermia/drowning, ${ }^{22}$ and miscellaneous. The classification process was done using a hierarchical system of diagnosis and procedure code criteria (Appendix Table E1) to create mutually exclusive groups. After initial examination, 2 groups were excluded from further analysis. The trauma/hypothermia/drowning group had an insufficient volume of admission records (no year with $>7$ admissions nationwide) to be analytically useful. The miscellaneous group (those who had a recorded ECMO procedure code but none of the related diagnosis or procedure codes that would help identify the indication for ECMO) was reviewed in detail. The primary diagnosis and procedure codes present in these records revealed no plausible indication for ECMO. The mortality rates and length of hospital stay recorded in these records was not consistent with ECMO use. Therefore, it was thought that this group likely represented the fraction of records in which an ECMO procedure code was entered erroneously. This process left 5 remaining groups for analysis, hereafter referred to by the following abbreviated labels: postcardiotomy, heart transplant, lung transplant, cardiogenic shock, and respiratory failure.

Discharge weights were used to create national estimates for the use of ECMO within the NIS stratified sampling frame, and ECMO use was analyzed by group and year. Primary outcome measures included inpatient length of stay (variable LOS), total inpatient hospital charges (variable TOTCHG), calculated mean hospital charges per day, and in-hospital mortality (variable DIED). Discharge disposition (for patients discharged alive) was defined using the variable DISPUNIFORM as discharge to home, transfer to another acute-care hospital, or discharge to rehabilitation (including skilled nursing facility, long-term subacute care hospital, or home-based nursing care), and then summarized as discharge to home or nonhome.
Hospital charges and charges per day were indexed to inflation by adjusting all values to 2009 dollars using the Bureau of Labor Statistics Consumer Price Index (CPI). The CPI subindex specific to inpatient hospital services was used with a baseline of December 1996 taken as 100, and yearly CPI values were used to generate a conversion factor to 2009 dollars. ${ }^{23}$ For example, the CPI for inpatient hospital services in 2000 is 113.8 ; in 2009, it is 203.54. Therefore, the conversion from 2000 dollars to 2009 dollars involves multiplying by $(203.564 \div 113.8)$, or 1.78879 .

\section{Statistical Analysis}

Because the stratified sampling frame of the NIS requires the use of advanced techniques (facilitated by PROC SURVEYMEANS in SAS; SAS Institute Inc, Cary, NC) to estimate variance, continuous variables are presented as mean \pm standard error. Multi-group comparisons were carried out using a 1-way analysis of variance for continuous variables and Pearson's chi-square test for categoric variables. Trends over time were examined using a Mann-Kendall test for trend ${ }^{24}$ (a nonparametric test to determine the presence and direction of a trend over time). A predetermined alpha of 0.05 was used as the threshold of statistical significance. Analyses were performed using SAS 9.3.

\section{RESULTS}

Overall, a total of 9243 admissions included ECMO intervention during the study period. After exclusion of the trauma/drowning $(\mathrm{n}=132)$ and miscellaneous $(\mathrm{n}=357)$ groups, 8753 admissions remained for analysis.

Figure 1 shows the temporal trend in cumulative national hospital charges for ECMO admissions, which increased significantly from $\$ 109.0$ million in 1998 to $\$ 764.7$ million in 2009 (test for trend $P=.0016$ ). Figure 2 shows the trend in number of ECMO admissions, which demonstrated a nonsignificant increase over the study period (test for trend, $P=.19$ ) from 742 in 1998 to 1621 in 2009.

In the entire study group, average length of stay was 18.3 \pm 1.3 days. Mean total charges were $\$ 344,009 \pm \$ 30,707$, with average charges per day of $\$ 40,588 \pm \$ 3099$. Figure 3 shows the temporal trends in mean total hospital charges and mean length of stay, both of which increased significantly over the study period (test for trend $P=.0032$ and .0321, respectively). In-hospital mortality increased over the study period from $33.1 \%$ in 1998 to $52.9 \%$ in 2009 , but this trend did not reach statistical significance $(P=.19)$.

Table 1 displays the size, baseline characteristics, and outcome variables of each group. Of note, the postcardiotomy group was older, with a greater male predominance, and included the greatest proportion of admissions from a nonteaching hospital. This group had the shortest length of stay and lowest total charges. Compared with the post-cardiotomy group, the cardiogenic shock, respiratory failure, and lung transplant groups had longer lengths of stay, higher total charges, higher rates of in-hospital mortality, and higher proportions of patients with a nonhome discharge disposition.

Figure 4 shows the temporal trends in relative frequency of ECMO use by group over the study period. Over the study period, a shift in case mix was observed, with a relative decrease in the post-cardiotomy group and increases in 


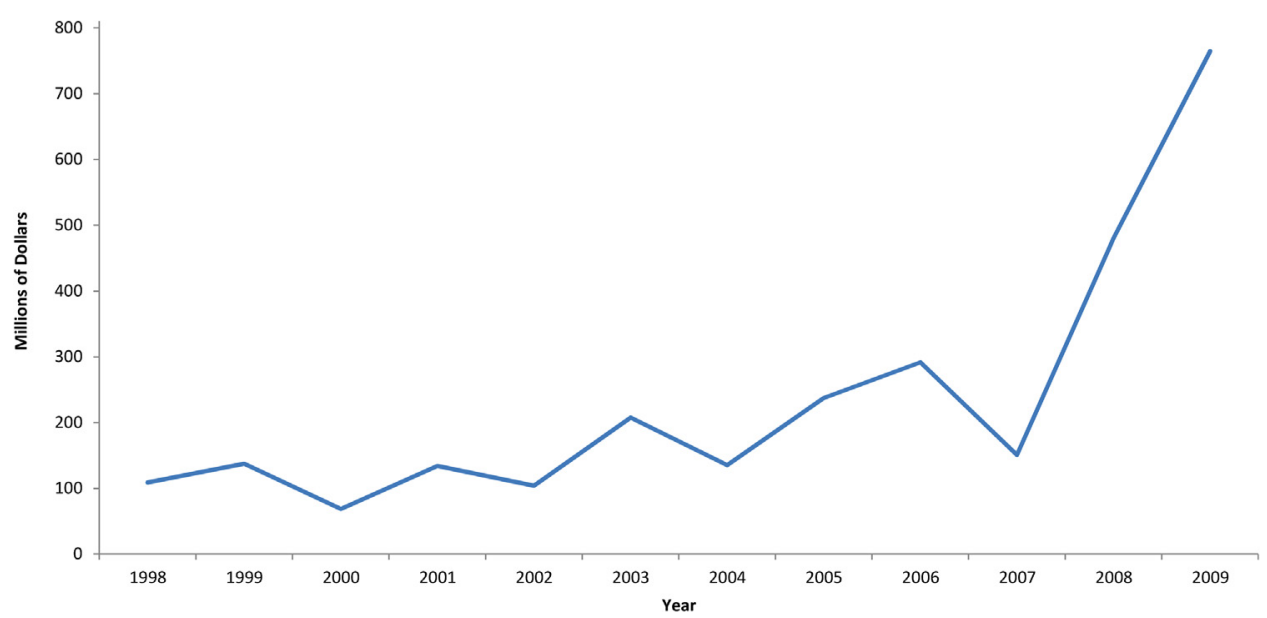

FIGURE 1. Cumulative national hospital charges (in millions of inflation-adjusted 2009 dollars) for ECMO admissions increased over the study period (test for trend $P=.0016$ ).

the cardiogenic shock, respiratory failure, and lung transplant groups.

\section{DISCUSSION}

The principal finding of this study is that a dramatic increase in the total resource use associated with ECMO use was observed over the study period. However, the causes of this increase appear to be multifactorial. ECMO is being used in a greater absolute number of admissions, but this increasing trend was not statistically significant. The significant increase in total hospital charges for ECMO admissions was largely due to the use of ECMO in admissions that demonstrated trends of statistically significant increases in length of stay and total hospital charges. In addition, these increases have been associated with a relative shift in the case-mix of ECMO use toward patient groups with worse clinical outcomes, longer hospital length of stay, and greater hospital charges. During this shift, in-hospital mortality in ECMO patients increased, although this trend did not reach statistical significance.

Most notable, the balance between the 2 largest patient groups has shifted over the study period. In 1998, the post-cardiotomy group comprised $80 \%$ of all ECMO admissions and cardiogenic shock comprised $16 \%$; in 2009, the balance was nearly equal $(40 \%$ post-cardiotomy vs $39 \%$ cardiogenic shock).

Respiratory failure has gone from being a trivial contributor to national ECMO use ( $<1$ in 20 ECMO admissions in $1998)$ to a small but growing contributor group $(>1$ in 8 in 2009). This trend may become even more pronounced in

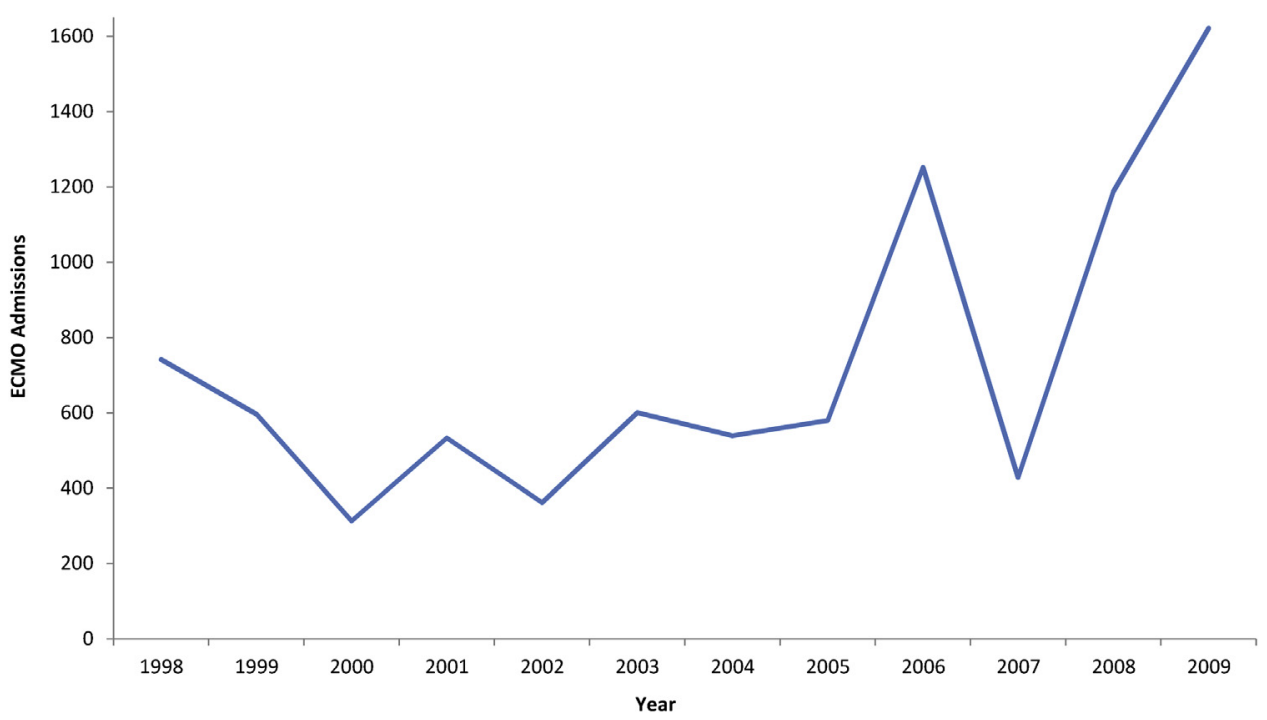

FIGURE 2. Overall number of ECMO admissions per year (no significant increase over time, test for trend $P=.19$ ). ECMO, Extracorporeal membrane oxygenation. 

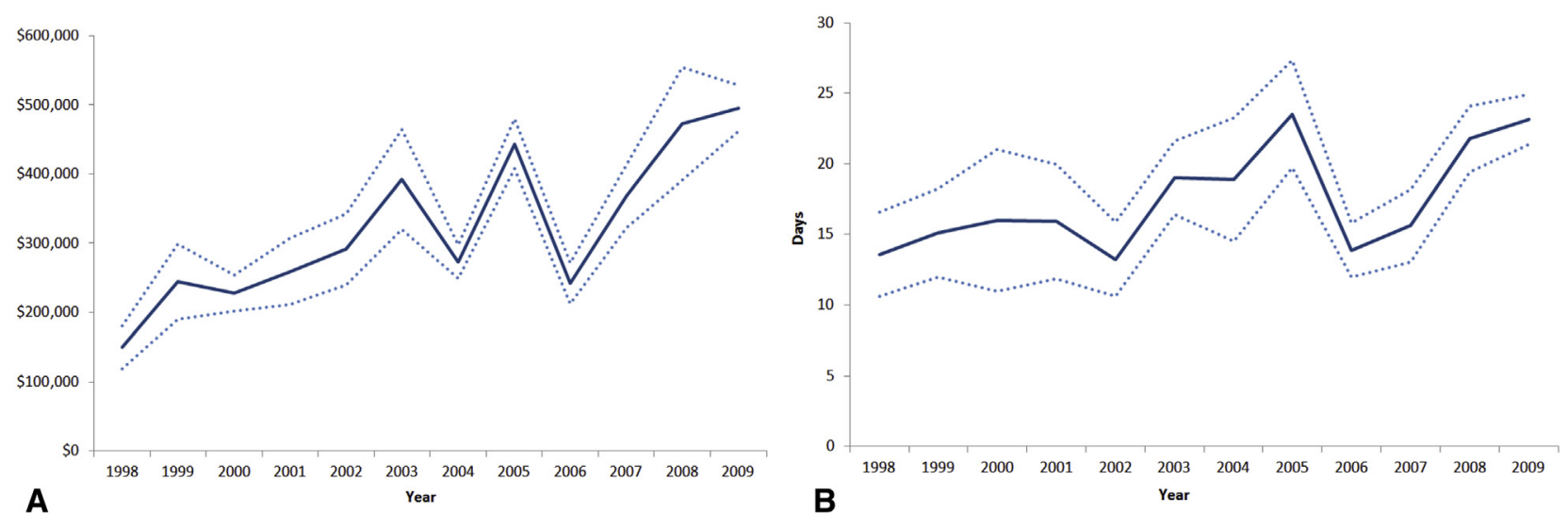

FIGURE 3. Total charges per admission (A) and length of stay (B) depicted as mean (solid lines) \pm standard error (dotted lines). Both measures increased significantly over the study period (test for trend $P=.0032$ and $P=.0321$, respectively).

future years, because recent trials of the use of ECMO for respiratory failure ${ }^{10,25,26}$ and sepsis ${ }^{27,28}$ showing benefits compared with standard care may prompt even greater enthusiasm for these ECMO indications.

These results share some similarities with recent analyses of ECMO use in the pediatric population. Karamlou and colleagues $^{29}$ used the Kids' Inpatient Database, a similarly constructed national administrative database to the NIS, and found 6333 pediatric admissions involving ECMO within a study period encompassing 4 years of data (an average of 1583 per year). ${ }^{29}$ Our finding of 9243 adult admissions involving ECMO within a study period encompassing 12 years of data ( 770 per year) is consistent with the prior finding that adult ECMO volume is lower than pediatric volume. ${ }^{3}$ The overall in-hospital mortality rate in this study $(51.0 \%)$ did not differ substantially from that in the study by Karamlou and colleagues (45.6\%), although a single- institution retrospective study of pediatric ECMO $(\mathrm{n}=95)$ observed lower in-hospital mortality $(27 \%) .^{30}$ Neither of these studies provide comparison data on resource use trends in pediatric ECMO.

\section{Study Limitations}

Substantial limitations to this study exist as a result of structural features of the NIS database. First, ICD-9-CM codes do not differentiate between venoarterial or venovenous ECMO. Although associated diagnosis codes may be suggestive of which type of ECMO would be required (eg, patients with respiratory patients might be more likely to receive venovenous ECMO, and patients post-cardiotomy might be more likely to receive venoarterial ECMO), no universal assumptions can be made about which ECMO strategy was used, such that this analysis is not able to examine this potential dimension of heterogeneity within

TABLE 1. Characteristics and outcomes of extracorporeal membrane oxygenation admissions by group

\begin{tabular}{|c|c|c|c|c|c|c|c|}
\hline & Post-cardiotomy & Heart transplant & Lung transplant & Cardiogenic shock & Respiratory failure & & Overall \\
\hline & $n=4493$ & $n=214$ & $\mathrm{n}=563$ & $\mathrm{n}=\mathbf{2 5 0 5}$ & $\mathbf{n}=\mathbf{9 7 7}$ & $\boldsymbol{P}$ & $n=8753$ \\
\hline Male & $64.8 \%$ & $51.2 \%$ & $54.0 \%$ & $57.5 \%$ & $49.8 \%$ & .0002 & $60.0 \%$ \\
\hline White & $73.4 \%$ & $81.8 \%$ & $80.8 \%$ & $68.8 \%$ & $67.8 \%$ & .087 & $72.2 \%$ \\
\hline Age & $60.3 \pm 0.5$ & $47.7 \pm 2.1$ & $50.3 \pm 1.2$ & $48.9 \pm 0.8$ & $41.2 \pm 1.1$ & $<.0001$ & $53.9 \pm 0.4$ \\
\hline Nonelective admission & $51.8 \%$ & $67.7 \%$ & $83.1 \%$ & $74.5 \%$ & $81.3 \%$ & $<.0001$ & $36.3 \%$ \\
\hline Hospital type & & & & & & $<.0001$ & \\
\hline Rural & $0.0 \%$ & $0.0 \%$ & $0.0 \%$ & $0.0 \%$ & $0.2 \%$ & & $0.03 \%$ \\
\hline Urban, nonteaching & $13.7 \%$ & $0.0 \%$ & $0.0 \%$ & $9.4 \%$ & $6.6 \%$ & & $10.0 \%$ \\
\hline Urban, teaching & $86.3 \%$ & $100.0 \%$ & $100.0 \%$ & $90.6 \%$ & $93.2 \%$ & & $89.9 \%$ \\
\hline Payer & & & & & & $<.0001$ & \\
\hline Medicare & $19.0 \%$ & $8.3 \%$ & $29.1 \%$ & $9.7 \%$ & $3.0 \%$ & & $11.6 \%$ \\
\hline Medicaid & $31.3 \%$ & $30.2 \%$ & $14.8 \%$ & $36.8 \%$ & $44.8 \%$ & & $36.7 \%$ \\
\hline Private & $41.1 \%$ & $45.3 \%$ & $51.3 \%$ & $44.5 \%$ & $44.9 \%$ & & $43.3 \%$ \\
\hline Self-pay/other & $8.7 \%$ & $16.2 \%$ & $4.8 \%$ & $9.1 \%$ & $7.3 \%$ & & $8.4 \%$ \\
\hline In-hospital mortality & $44.2 \%$ & $41.9 \%$ & $54.0 \%$ & $64.0 \%$ & $49.3 \%$ & $<.0001$ & $51.0 \%$ \\
\hline Nonhome discharge & $50.6 \%$ & $48.0 \%$ & $78.9 \%$ & $65.8 \%$ & $67.3 \%$ & $<.0001$ & $58.6 \%$ \\
\hline Length of stay (d) & $12.9 \pm 0.9$ & $45.8 \pm 8.7$ & $38.1 \pm 3.4$ & $19.0 \pm 1.5$ & $23.5 \pm 1.7$ & $<.0001$ & $18.3 \pm 1.3$ \\
\hline Total charges & $\$ 273,429 \pm \$ 31,361$ & $\$ 722,123 \pm \$ 57,494$ & $\$ 702,973 \pm \$ 50,502$ & $\$ 352,559 \pm \$ 29,037$ & $\$ 421,037 \pm \$ 39,018$ & $<.0001$ & $\$ 344,009 \pm \$ 30,707$ \\
\hline Charges per day & $\$ 41,872 \pm \$ 4050$ & $\$ 31,967 \pm \$ 5385$ & $\$ 79,286 \pm \$ 14,499$ & $\$ 37,489 \pm \$ 2684$ & $\$ 26,922 \pm \$ 2473$ & $<.0001$ & $\$ 40,588 \pm \$ 3099$ \\
\hline
\end{tabular}




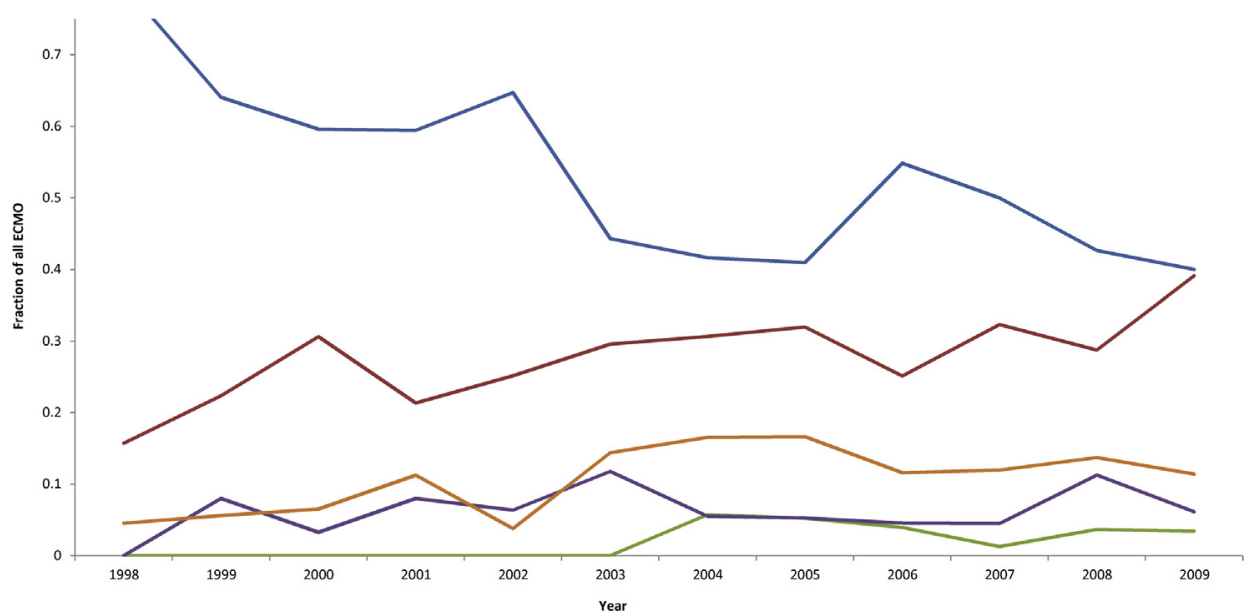

FIGURE 4. Relative frequency of ECMO use for each group, as a fraction of all ECMO admissions: post-cardiotomy (blue line), cardiogenic shock (red line), respiratory failure (orange line), lung transplant (purple line), and heart transplant (green line). ECMO, Extracorporeal membrane oxygenation.

the ECMO population. Second, resource use information is available only for the entire hospital admission, which precludes knowledge of the duration of ECMO use or timing of weaning from ECMO. Thus, this analysis cannot differentiate hospital days or charges incurred during ECMO from the remainder of the hospitalization, so it constitutes an analysis of resource use in admissions where ECMO is used, but not an analysis of ECMO-specific resource use. Third, the NIS sampling frame and data variables do change slightly from year to year, and trend analyses using NIS data must consider this limitation. We sought to mitigate this effect by ensuring that ICD-9 code definitions for ECMO did not change during the study period (39.65 was in use from 1988 onward; 39.66 was in use from 1990 onward) and by designing the study period such that it did not cross the greatest revision in the NIS data structure, which occurred in 1998. Also, we adjusted hospital charges using the inpatient hospital services subindex of the CPI to minimize the contributions of inflation and broader increases in health care expenditures to the observed increases in ECMOrelated resource use.

Fourth, total hospital charges as reported in the NIS represent hospital billing, not actual expenditures or reimbursement. The complex, nonlinear relationships among hospital charges, hospital costs, insurance reimbursement, and patient co-payments complicate the extrapolation of these results to an estimation of the true societal cost for ECMO. In addition, the structure of the NIS as an admissions-based database results in the potential that total charges are underestimated. In the subset of patients whose discharge disposition was transfer to another acute-care facility, some of these discharges may represent transfer to another institution with a higher level of care during the ECMO run. In this instance, total charges could be split between 2 admission records or may not be captured if the receiving institution does not participate in the $20 \%$ stratified sampling frame of the NIS. This limitation primarily affects the accuracy of an analysis of the absolute magnitude of resource use; it would be expected to be less significant when viewed from the perspective of analyzing relative shifts and trends over time. However, to the degree that the relationship among charges, costs, and other parameters does not change drastically over short periods of time, hospital charges at minimum are useful for analysis of resource use trends, allow for aggregation of data at the national level, and give some sense of the magnitude of resource use devoted to this therapy. Many prior investigations have established a precedent for this analytic approach in the face of these limitations. ${ }^{31-35}$

\section{CONCLUSIONS}

Despite these limitations, this analysis is useful in demonstrating the relative trends in ECMO use and their resource use implications. These results have practice and policy implications at the institutional, state, and national levels, particularly in the face of increasing pressure for complex medical interventions to demonstrate comparative effectiveness and value, and for systems to restrain the growth of health care expenditures. As ECMO use as a support therapy for critically ill adults continues to expand, a more thorough understanding of its effectiveness, costs, and demands on healthcare resources is needed. These results also will inform further studies, including more ECMO group-specific cost-effectiveness analyses, ${ }^{9}$ to refine our application of these findings to broader discussions about health care resource use.

\section{References}

1. Michaels AJ, Hill JG, Bliss D, Sperley BP, Young BP, Quint P, et al. Pandemic flu and the sudden demand for ECMO resources: a mature trauma program can provide surge capacity in acute critical care crises. J Trauma Acute Care Surg. 2013; 74:1493-7. 
2. Hill JD, O'Brien TG, Murray JJ, Dontigny L, Bramson ML, Osborn JJ, et al. Prolonged extracorporeal oxygenation for acute post-traumatic respiratory failure (shock-lung syndrome). Use of the Bramson membrane lung. $N$ Engl J Med. 1972;286:629-34.

3. Paden ML, Conrad SA, Rycus PT, Thiagarajan RR. Extracorporeal life support organization registry report 2012. ASAIO J. 2013;59:202-10.

4. Mishra V, Svennevig JL, Bugge JF, Andresen S, Mathisen A, Karlsen H, et al. Cost of extracorporeal membrane oxygenation: evidence from the Rikshospitalet University Hospital, Oslo, Norway. Eur J Cardiothorac Surg. 2010;37:339-42.

5. Roberts TE. Economic evaluation and randomised controlled trial of extracorporeal membrane oxygenation: UK collaborative trial. The Extracorporeal Membrane Oxygenation Economics Working Group. BMJ. 1998;317:911-5.

6. Petrou S, Bischof M, Bennett C, Elbourne D, Field D, McNally H. Cost-effectiveness of neonatal extracorporeal membrane oxygenation based on 7-year results from the United Kingdom Collaborative ECMO Trial. Pediatrics. 2006; 117:1640-9.

7. Schumacher RE, Roloff DW, Chapman R, Snedecor S, Bartlett RH. Extracorporeal membrane oxygenation in term newborns. A prospective cost-benefit analysis. ASAIO J. 1993;39:873-9.

8. Crow S, Fischer AC, Schears RM. Extracorporeal life support: utilization, cost, controversy, and ethics of trying to save lives. Semin Cardiothorac Vasc Anesth. 2009; 13:183-91.

9. Peek GJ, Elbourne D, Mugford M, Tiruvoipati R, Wilson A, Allen E, et al. Randomised controlled trial and parallel economic evaluation of conventional ventilatory support versus extracorporeal membrane oxygenation for severe adult respiratory failure (CESAR). Health Technol Assess. 2010;14:1-46.

10. Peek GJ, Mugford M, Tiruvoipati R, Wilson A, Allen E, Thalanany MM, et al. Efficacy and economic assessment of conventional ventilatory support versus extracorporeal membrane oxygenation for severe adult respiratory failure (CESAR): a multicentre randomised controlled trial. Lancet. 2009;374:1351-63.

11. HCUP Nationwide Inpatient Sample (NIS). Healthcare Cost and Utilization Project (HCUP). 2002-2009. Rockville, MD: Agency for Healthcare Research and Quality; 2011.

12. Pokersnik JA, Buda T, Bashour CA, Gonzalez-Stawinski GV. Have changes in ECMO technology impacted outcomes in adult patients developing postcardiotomy cardiogenic shock? J Card Surg. 2012;27:246-52.

13. Rastan AJ, Dege A, Mohr M, Doll N, Falk V, Walther T, et al. Early and late outcomes of 517 consecutive adult patients treated with extracorporeal membrane oxygenation for refractory postcardiotomy cardiogenic shock. J Thorac Cardiovasc Surg. 2010;139:302-11. 311.e1.

14. Kittleson MM, Patel JK, Moriguchi JD, Kawano M, Davis S, Hage A, et al. Heart transplant recipients supported with extracorporeal membrane oxygenation: outcomes from a single-center experience. J Heart Lung Transplant. 2011;30: 1250-6.

15. Shafii AE, Mason DP, Brown CR, Vakil N, Johnston DR, McCurry KR, et al. Growing experience with extracorporeal membrane oxygenation as a bridge to lung transplantation. ASAIO J. 2012;58:526-9.

16. Javidfar J, Brodie D, Iribarne A, Jurado J, Lavelle M, Brenner K, et al. Extracorporeal membrane oxygenation as a bridge to lung transplantation and recovery. J Thorac Cardiovasc Surg. 2012;144:716-21.

17. Toyoda Y, Bhama JK, Shigemura N, Zaldonis D, Pilewski J, Crespo M, et al. Efficacy of extracorporeal membrane oxygenation as a bridge to lung transplantation. J Thorac Cardiovasc Surg. 2013;145:1065-70.

18. Mason DP, Boffa DJ, Murthy SC, Gildea TR, Budev MM, Mehta AC, et al. Extended use of extracorporeal membrane oxygenation after lung transplantation. J Thorac Cardiovasc Surg. 2006;132:954-60.
19. Lindskov C, Jensen RH, Sprogoe P, Klaaborg KE, Kirkegaard H, Severinsen IK, et al. Extracorporeal membrane oxygenation in adult patients with severe acute respiratory failure. Acta Anaesthesiol Scand. 2013;57:303-11.

20. Rehder KJ, Turner DA, Bonadonna D, Walczak RJ, Rudder RJ, Cheifetz IM. Technological advances in extracorporeal membrane oxygenation for respiratory failure. Expert Rev Respir Med. 2012;6:377-84.

21. Sadahiro T, Oda S, Nakamura M, Hirayama Y, Watanabe E, Tateishi Y, et al Trends in and perspectives on extracorporeal membrane oxygenation for severe adult respiratory failure. Gen Thorac Cardiovasc Surg. 2012;60: 192-201.

22. Morita S, Inokuchi S, Yamagiwa T, Iizuka S, Yamamoto R, Aoki H, et al. Efficacy of portable and percutaneous cardiopulmonary bypass rewarming versus that of conventional internal rewarming for patients with accidental deep hypothermia. Crit Care Med. 2011;39:1064-8.

23. Bureau of Labor Statistics. Consumer Price Index Detailed Reports 1998-2009. Available at: http://www.bls.gov/cpi/cpi_dr.htm. Accessed July 24, 2013.

24. Onoz B, Bayazit M. The power of statistical tests for trend detection. Turkish J Eng Env Sci. 2003;27:247-51.

25. Peek GJ, Clemens F, Elbourne D, Firmin R, Hardy P, Hibbert C, et al. CESAR: conventional ventilatory support vs extracorporeal membrane oxygenation for severe adult respiratory failure. BMC Health Serv Res 2006;6:163.

26. Davies A, Jones D, Bailey M, Beca J, Bellomo R, Blackwell N, et al. Extracorporeal membrane oxygenation for 2009 influenza A(H1N1) acute respiratory distress syndrome. JAMA. 2009;302:1888-95.

27. Bréchot N, Luyt C-E, Schmidt M, Leprince P, Trouillet J-L, Léger P, et al Venoarterial extracorporeal membrane oxygenation support for refractory cardiovascular dysfunction during severe bacterial septic shock. Crit Care Med. 2013;41:1616-26.

28. Huang C-T, Tsai Y-J, Tsai P-R, Ko W-J. Extracorporeal membrane oxygenation resuscitation in adult patients with refractory septic shock. J Thorac Cardiovasc Surg. 2012 Sep 6 [Epub ahead of print].

29. Karamlou T, Vafaeezadeh M, Parrish AM, Cohen GA, Welke KF, Permut L, et al. Increased extracorporeal membrane oxygenation center case volume is associated with improved extracorporeal membrane oxygenation survival among pediatric patients. J Thorac Cardiovasc Surg. 2013; $145: 470-5$.

30. Chrysostomou C, Morell VO, Kuch BA, O’Malley E, Munoz R, Wearden PD Short- and intermediate-term survival after extracorporeal membrane oxygenation in children with cardiac disease. J Thorac Cardiovasc Surg. 2013;146: 317-25.

31. Opotowsky AR, Siddiqi OK, Webb GD. Trends in hospitalizations for adults with congenital heart disease in the U.S. J Am Coll Cardiol. 2009;54:460-7.

32. Al-Rawajfah OM, Hewitt JB, Stetzer F, Cheema J. Length of stay and charges associated with health care-acquired bloodstream infections. Am J Infect Control. 2012;40:227-32.

33. Baaj AA, Uribe JS, Nichols TA, Theodore N, Crawford NR, Sonntag VKH, et al. Health care burden of cervical spine fractures in the United States: analysis of a nationwide database over a 10-year period. J Neurosurg Spine. 2010; 13:61-6.

34. Kozma CM, Dickson M, Raut MK, Mody S, Fisher AC, Schein JR, et al. Economic benefit of a 1-day reduction in hospital stay for community-acquired pneumonia (CAP). J Med Econ. 2010;13:719-27.

35. Eslami MH, McPhee JT, Simons JP, Schanzer A, Messina LM. National trends in utilization and postprocedure outcomes for carotid artery revascularization 2005 to 2007. J Vasc Surg. 2011;53:307-15. 
APPENDIX TABLE E1. Diagnosis and procedure code-based criteria to define extracorporeal membrane oxygenation groups

\begin{tabular}{|c|c|c|c|c|}
\hline Group & Code type & Code & Description & Related criteria \\
\hline \multirow[t]{5}{*}{ Post-cardiotomy } & ICD-9-CM Vol 3 (Procedure) & $35 . x$ & Operations on valves and septa of heart & $\begin{array}{l}\text { Absence of heart or lung transplant } \\
\text { procedure codes }\end{array}$ \\
\hline & ICD-9-CM Vol 3 (Procedure) & $36 . x$ & Operations on vessels of heart & \\
\hline & ICD-9-CM Vol 3 (Procedure) & 37.1 & Cardiotomy and pericardiotomy & \\
\hline & ICD-9-CM Vol 3 (Procedure) & $37.3 x$ & $\begin{array}{l}\text { Pericardiectomy and excision of lesion of } \\
\text { heart }\end{array}$ & \\
\hline & ICD-9-CM Vol 3 (Procedure) & 441.x & $\begin{array}{l}\text { Major aortic dissection or aneurysm } \\
\text { repair }\end{array}$ & \\
\hline Heart transplant & ICD-9-CM Vol 3 (Procedure) & 37.51 & Heart transplantation & $\begin{array}{l}\text { Absence of lung transplant procedure } \\
\text { codes }\end{array}$ \\
\hline \multirow[t]{2}{*}{ Lung transplant } & ICD-9-CM Vol 3 (Procedure) & 33.5 & Lung transplantation & $\begin{array}{l}\text { Absence of heart transplant procedure } \\
\text { code }\end{array}$ \\
\hline & ICD-9-CM Vol 3 (Procedure) & 33.6 & Heart-lung transplantation & \\
\hline \multirow[t]{7}{*}{ Cardiogenic shock } & CCS diagnoses & 107 & Cardiac arrest and ventricular fibrillation & $\begin{array}{l}\text { Absence of cardiac surgical, heart, or } \\
\text { lung transplant procedure codes }\end{array}$ \\
\hline & CCS diagnoses & 108 & Congestive heart failure; nonhypertensive & \\
\hline & CCS diagnoses & 100 & Acute myocardial infarction & \\
\hline & CCS diagnoses & 97 & $\begin{array}{l}\text { Pericarditis, endocarditis, and } \\
\text { myocarditis; cardiomyopathy }\end{array}$ & \\
\hline & CCS diagnoses & 106 & Cardiac dysrhythmias & \\
\hline & CCS diagnoses & 101 & $\begin{array}{l}\text { Coronary atherosclerosis and other heart } \\
\text { disease }\end{array}$ & \\
\hline & CCS diagnoses & 103 & Pulmonary heart disease & \\
\hline \multirow[t]{7}{*}{ Respiratory failure } & CCS diagnoses & 131 & $\begin{array}{l}\text { Respiratory failure, insufficiency, or } \\
\text { arrest (adult) }\end{array}$ & $\begin{array}{l}\text { Absence of cardiac surgical, heart, or } \\
\text { lung transplant procedure codes }\end{array}$ \\
\hline & CCS diagnoses & 122 & Pneumonia & \\
\hline & CCS diagnoses & 123 & Influenza & \\
\hline & CCS diagnoses & 130 & Pneumothorax or pulmonary collapse & \\
\hline & CCS diagnoses & 132 & Lung disease due to external agents & \\
\hline & CCS diagnoses & 126 & Other upper respiratory infections & \\
\hline & CCS diagnoses & 3 & Bacterial infection & \\
\hline Trauma/drowning & CCS diagnoses & $2601-2615$ & $\begin{array}{l}\text { ICD-9-CM E-codes for trauma and } \\
\text { drowning }\end{array}$ & $\begin{array}{l}\text { Absence of cardiac surgical, heart, or } \\
\text { lung transplant procedure codes } \\
\text { Absence of diagnosis codes for } \\
\text { respiratory failure or cardiogenic } \\
\text { shock }\end{array}$ \\
\hline Miscellaneous & & & & $\begin{array}{l}\text { Absence of codes to qualify for any of } 6 \\
\text { above groups }\end{array}$ \\
\hline
\end{tabular}

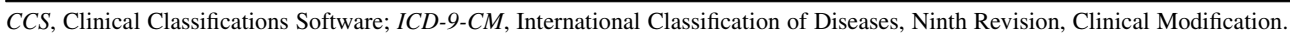

